\section{Technique for Improving Marketable Yield and Quality of Hydroponically Forced Witloof Chicory}

\author{
Zhi Yi Tan and Kenneth A. Corey \\ Department of Plant and Soil Sciences, University of Massachusetts, \\ Amherst, MA 01003
}

\begin{abstract}
Additional index words. belgian endive, chicon, conventional forcing, mechanical stress, Cichorium intybus
\end{abstract}

\begin{abstract}
A method was developed to improve the yield and quality of chicons of witloof chicory (Cichorium intybus L.) forced hydroponically from roots taken following long-term storage. The method combines the use of a resilient material (polyurethane foam) with the application of pressure to the developing chicons. At the start of forcing, weights of $0,150,300,450$, and 900 g/root were applied to the crown and maintained until harvest. Marketable yields and density of chicons of the late-forcing cultivar Faro increased with increasing weight applied. Increasing weight also significantly decreased the length : diameter ratio of chicons, an indicator of quality. Increased marketable yield and improved quality of 'Bea' (intermediate to late-forcing cultivar) chicons were achieved with application of 450 g/root. The technique provides a tool for improving economic yields of late-season, hydroponically forced witloof chicory.
\end{abstract}

Traditional methods for forcing witloof chicory involve the placement of roots in a bed of soil followed by covering roots with a soil-based medium (Nunhems Zaden, 1985; Ryder, 1979). Huyskes (1963) selected cultivars that would produce relatively tight chicons in the absence of soil covering. This breeding innovation led to great savings in labor formerly required for removing soil from chicons. Further improvement and testing of genotypes suited to forcing without cover (Lipps, 1976; Sarrazyn, 1976) enabled the development of methods for the hydroponic forcing of witloof chicory. This method depends on production of tight, well-shaped chicons in the absence of a cover. Hydroponic forcing is currently the most common method of commercial production in Holland, France, and in the United States. In Belgium, the scale of most forcing operations is relatively small, and many growers employ traditional forcing methods.

Some forcing operations attempt to provide chicons throughout the entire year. To achieve this goal, roots must be maintained in storage for long durations. Yield and quality of chicons are often quite low when roots

Received for publication 22 Jan. 1990. Paper no. 2961 of the Massachusetts Agricultural Experiment Station. Research supported by funds from U.S. Dept. of Agriculture, Grant no. 88-341693445. The cost of publishing this paper was defrayed in part by the payment of page charges. Under postal regulations, this paper therefore must be hereby marked advertisement solely to indicate this fact. it would be possible to develop mechanical techniques to improve the quality of hydroponically forced chicons, Our objective was to determine if pressure applied to the developing chicons would increase the marketable yield and quality of chicons forced from roots following long-term storage.

Roots of the cultivars Faro and Bea were grown in South Deerfield, Mass., in Summer 1988 and were harvested on 28 Sept., 120 days from planting. The day before harvest, shoots were trimmed to $\approx 5 \mathrm{~cm}$ above the crown. Following harvest, roots were held in storage at $1 \pm 2 \mathrm{C}$. Before forcing, roots were trimmed to $15 \mathrm{~cm}$ with $\approx 3 \mathrm{~cm}$ of senesced shoot remaining from harvest. Separate forcing experiments were initiated on 15 Mar. and 14 Apr. 1989 in a cold storage room maintained at $11 \pm 1 \mathrm{C}$. The forcing solution consisted of $2.7 \mathrm{~mm} \mathrm{Ca}\left(\mathrm{NO}_{3}\right)_{2}, 2.6$ $\mathrm{mm} \mathrm{MgSO}_{4}$, and $8.7 \mathrm{~mm} \mathrm{KNO}_{3}$ (De Proft et al., 1986) and was maintained to a depth of $5 \mathrm{~cm}$ in wooden trays (Corey et al., 1990). The solution was adjusted periodically to $\mathrm{pH}$ 7.0 by additions of $\mathrm{HCl}$.

Samples of 15 roots of 'Faro' were weighed and packed into plastic pots $(11.4 \mathrm{~cm}$ high $\times 15 \mathrm{~cm}$ diam) that then were placed in the forcing tray. Each pot had four 1.5-cm holes in the bottom and fourteen $1.5-\mathrm{cm}$ holes in the sides for adequate ventilation of roots and circulation of nutrient solution. A 7.6$\mathrm{cm}$-thick piece of polyurethane foam (air dry density $=0.017 \mathrm{~g} / \mathrm{cm}^{3}$ ) was placed on top of the shoots to provide a cushion for application of downward pressure. Individual pieces of 1.8-cm-thick plywood were placed on top of the foam pieces (excluding control) to provide a uniform pressure when bags of sand, were placed on top of the plywood. Foam and plywood pieces were weighed, and quantities of sand were placed in polyethylene bags to provide 0 (control), 150, 300, 


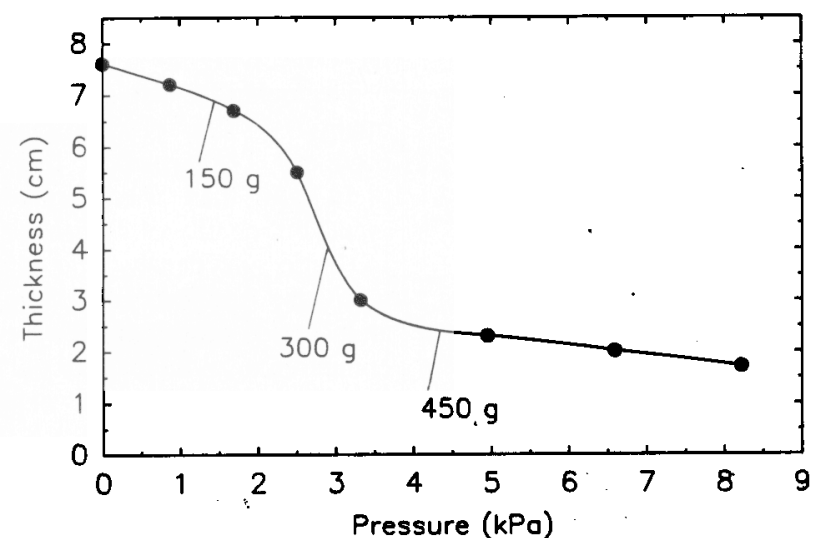

Fig. 2. Compression of polyurethane foam used as a growth cushion for treatments involving applied weight to developing chicons. Points represent means of two replications. Arrows denote regions of the curve corresponding to treatments used considering an average cross-sectional area of $9.6 \mathrm{~cm}^{2}$ for the root crown.

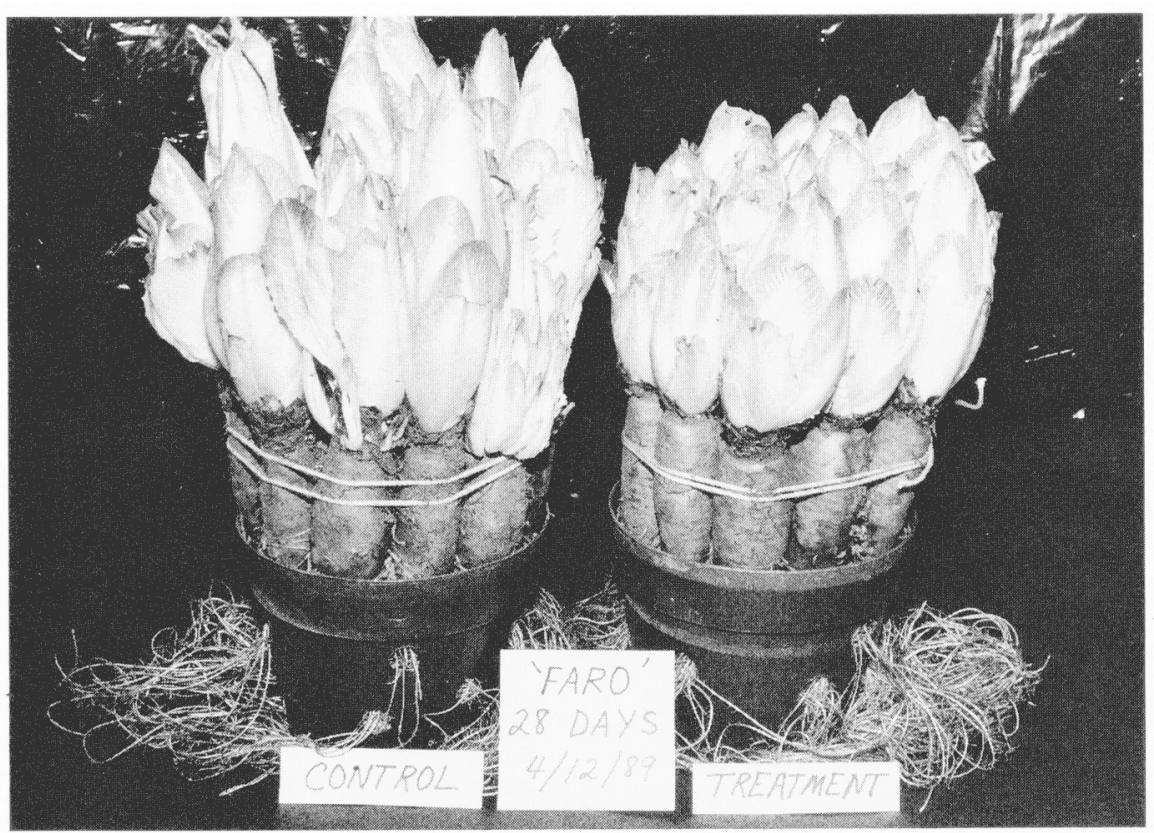

Fig. 3. Appearance of untreated (control) and treatcd $(450 \mathrm{~g} / \mathrm{root})$ chicons of 'Faro' on the day of harvest.-

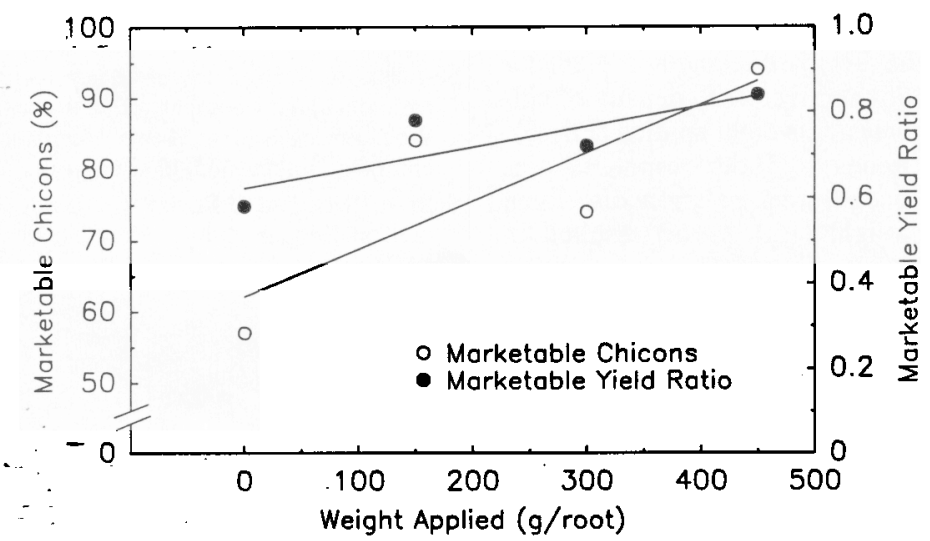

Fig. 4. Effect of applied weight on percent marketable chicons $(r=0.78 ; P=0.022)$ and marketable yield ratio $(r=0.80 ; P=0.017)$ of chicons of 'Faro'. Points represent means of duplicate 15-root samples.

and $450 \mathrm{~g} /$ root of applied weight. For example, a bag of sand weighing $1990 \mathrm{~g}$ was

placed on top of wood and foam pieces having a combined weight of $260 \mathrm{~g}$ to provide a $150 \mathrm{~g} /$ root treatment to 15 roots. Selection of treatments was based partly upon assumptions made to simulate initial pressures occurring at the beginning of conventional forcing with soil covering. The following calculation was made. An average root crown diameter of $3.5 \mathrm{~cm}$ and a soil cover of 10 $\mathrm{cm}$ give a volume of soil of $\approx 96 \mathrm{~cm}^{3}$ above the crown. With a soil bulk density of 1.5 $\mathrm{g} / \mathrm{cm}^{3}$ and a moisture content of $25 \%(\mathrm{w} / \mathrm{w})$, a total soil weight of $175 \mathrm{~g}$ would cover a single root. Treatments were not expressed as pressures because of the dynamics and irregularities of the forces involved and the variability in the cross-sectional area to which the downward forces were applied. The concept for the technique is illustrated in Fig. 1.

Two replications (pots) of each treatment were arranged in randomized complete blocks. Each pot contained 15 roots. Treatments were initiated at the beginning of forcing and were maintained until harvest 28 days later. Chicons were harvested flush with the crown and their total weight measured. A random sample of 10 chicons was selected for further measurements. Individual chicons from the random samples were weighed and measured for maximum circumference and length. Chicons were then wrapped and sealed in a plastic film and their volume measured by water displacement. Density was calculated from the weight and volume measurements. Chicons were unwrapped, trimmed, and graded to obtain a marketable yield ratio (marketable weight : total weight). The percentage of marketable chicons was based on the total number of roots forced. Chicons that were malformed, unfurled, or weighed $<60 \mathrm{~g}$ (Sterrett and Savage, 1989) were considered unmarketable.

Two additional experiments were conducted. One involved the use of 0,450 , and $900 \mathrm{~g} /$ root applied to 'Faro'. Another experiment was conducted using 0 and $450 \mathrm{~g} / \mathrm{root}$ treatments and 'Bea' and 'Faro'. Two replications of each treatment were used in both experiments. Other procedures for forcing and measurements were the same as those described.

To determine the compressibility of the foam, two pieces, each $60 \mathrm{~cm}^{2}$, were cut. A piece of $1.3-\mathrm{cm}$-thick plywood was placed over the foam, and weights ranging from 500 $\mathrm{g}$ to $5000 \mathrm{~g}$ were placed on the plywood. The thickness of the foam was measured after application of each weight.

Compression of the foam at the start of the forcing depended on the pressure applied (Fig. 2). The $150 \mathrm{~g} /$ root treatment $(\approx 1.5 \mathrm{kPa})$ compressed the foam very little $(<1 \mathrm{~cm})$. As chicons developed and exerted growth forces, additional compression of the foam occurred, and the chicons pushed the entire load upward. The $300 \mathrm{~g} /$ root treatment was near the middle of the region of maximum changes in the rate of compression (initial compression of $\approx 3.5 \mathrm{~cm}$ ) and the $450 \mathrm{~g} / \mathrm{root}$ treatment compressed the foam by $\approx 5 \mathrm{~cm}$, $\approx 65 \%$ of the compressed thickness (Fig. 2). For these treatments, developing chicons encountered increased resistance to growth ear- 


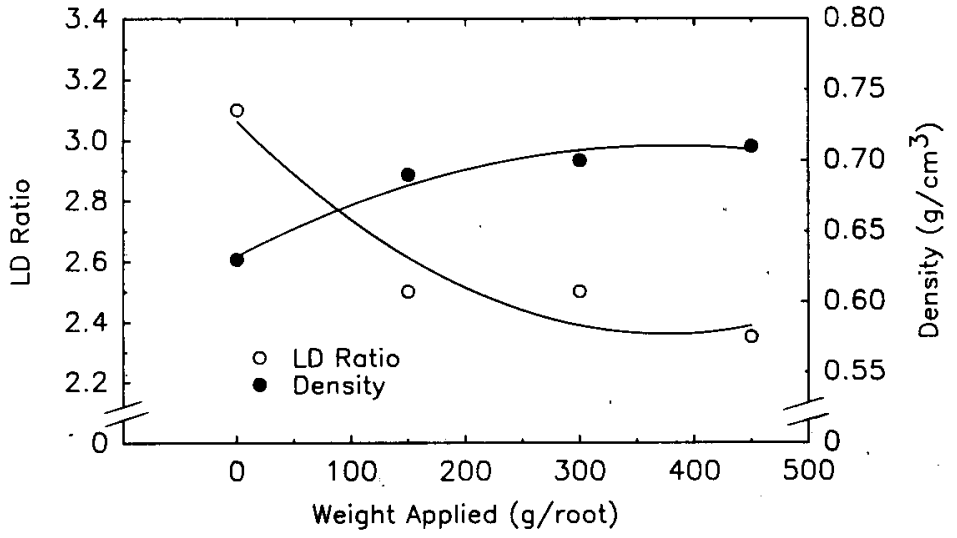

Fig. 5. Relationships of LD ratio (quadratic; $R^{2}=0.88$ ) and density (quadratic; $R^{2}=0.83$ ) of 'Faro' chicons with weight applied during forcing. Points represent means of duplicate 15-root samples.

Table 1. Effects of weight applied to developing chicons of 'Faro' and 'Bea' chicory on yield and quality.

\begin{tabular}{|c|c|c|c|c|}
\hline \multirow[b]{2}{*}{$\begin{array}{l}\text { Treatment } \\
\text { variable }\end{array}$} & \multicolumn{4}{|c|}{ Response variable ${ }^{z}$} \\
\hline & $\begin{array}{l}\text { Marketable } \\
\text { chicons }(\%)\end{array}$ & $\begin{array}{l}\text { Marketable } \\
\text { yield ratio }\end{array}$ & $\begin{array}{l}\text { LD ratio } \\
\text { of chicons }\end{array}$ & $\begin{array}{c}\text { Density of } \\
\text { chicon }\left(\mathrm{g} / \mathrm{cm}^{3}\right)\end{array}$ \\
\hline Cultivar & NS & $* *$ & NS & NS \\
\hline Faro & 79 & 0.72 & 2.58 & 0.61 \\
\hline Bea & 73 & 0.60 & 2.52 & 0.62 \\
\hline Weight & + & $* *$ & $* *$ & $* *$ \\
\hline None & 71 & 0.59 & 2.85 & 0.56 \\
\hline $450 \mathrm{~g} / \mathrm{root}$ & 80 & 0.73 & 2.24 & 0.66 \\
\hline Cultivar $x$ wt & NS & NS & NS & $*$ \\
\hline
\end{tabular}

${ }^{2}$ Values represent means of four observations for the treatment variables cultivar and weight. Each observation was the mean of a sample of 35 and 29 roots for 'Faro' and 'Bea', respectively. $\mathrm{LD}=$ length : diameter.

,$+ * * *$, NSStatistically significant at $P=0.1,0.05$, and 0.01 and not significant, respectively.

lier than when $150 \mathrm{~g} /$ root was applied. However, growth forces were more than sufficient to overcome the pressures applied.

At harvest, ungraded chicons of the 450 $\mathrm{g} /$ root treatment exhibited the highest visual quality (Fig. 3). Untreated chicons appeared longer and looser than any of those from treatments involving applied weight. Total yield of ungraded chicons was not significantly affected by treatment (overall mean $=86 \pm 8 \mathrm{~g} /$ chicon). However, percent marketable chicons and marketable yield ratio increased linearly with increasing weight applied $(r=0.78 ; P \leq 0.022$ and $r=0.80$; $P \leq 0.017$, respectively), $450 \mathrm{~g} / \mathrm{root}$ giving the highest economic yields (Fig. 4). Since marketable yield did not plateau within the 0 to $450 \mathrm{~g} /$ root range, a follow-up experiment included a $900 \mathrm{~g} /$ root treatment to determine if further improvements in marketable yield could be obtained. Application of 900 $\mathrm{g} /$ root resulted in significantly fewer marketable chicons $(69 \%)$ than $450 \mathrm{~g} /$ root $(86 \%)$ and about the same as the control $(73 \%)$, suggesting that the maximum response is probably near $450 \mathrm{~g} /$ root for the size and physiological status of 'Faro' roots used in the experiments.

Marketable yield ratio increased more with increasing weight applied than did percent marketable chicons (Fig. 4). This result was due to the higher quality chicons and decreased trim loss obtained from application of weight. Improved quality also was reflected in the decreased length : diameter ratio (LD ratio) and increased density of chicons with increasing weight applied (Fig. 5). Significant trends for both responses presented are second-order polynomials. Even the lowest weight $(150 \mathrm{~g} / \mathrm{root})$ resulted in significantly shorter, stockier chicons than those receiving no application of weight.

The technique also improved the yield and quality of 'Bea' chicons (Table 1). 'Faro' produced a significantly higher marketable yield ratio than ' $B$ ea' regardless of treatment, but quality of chicons as measured by LD ratio and density was similar for both cultivars. Application of weight resulted in an increased density of $0.14 \mathrm{~g} \cdot \mathrm{cm}^{-3}$ for 'Faro' compared to an increase of only $0.06 \mathrm{~g} \cdot \mathrm{cm}^{-3}$ for 'Bea', illustrating the nature of the cultivar $\times$ weight interaction.

Despite breeding efforts to select genotypes suited to forcing without cover, significant improvement in economic yields and quality of hydroponically forced witloof chicory is still achievable using manipulations of cultural practices. A simple technique involving the application of mechanical pressure to developing chicons significantly improved marketable yields and quality of intermediate- and late-forcing cultivars. Suitability of the technique applied to different stages of maturity, storage durations, and cultivars remains to be evaluated. Finally, it will be of basic interest to understand the physiological mechanisms upon which the success of the technique is based.

\section{Literature Cited}

Corey, K.A., D.J. Merchant, and L.F. Whitney. 1990. Witloof chicory: Anew vegetable crop in the United States. Advances in new crops. Timber Press, Portland, Ore. p. 414-418.

Daemen, B. 1987. Witloof chicory-an alternative crop. Amer. Veg. Grower, Jan. p. 34-35.

De Proft, M., J. De Greef, K. Van Nerum, and G. Goffings. 1986. Ethylene in the production of Belgian endive. HortScience 21:1132-1133.

Huyskes, J.A. 1963. Improvement of witloof for forcing without covering soil (in Dutch). Meded. Dir. Tuin. 202.

Lipps, J. 1976. Some experiences with new varieties of witloof for forcing without soil covering. Proc. Eucarpia Meet. Leafy Vegetables, Wageningen, Holland, 15-18 Mar. p. 40-47.

Nunhems Zaden. 1985. The growing and forcing of chicory witloof. Nunhems Zaden, Haelen, Holland.

Ryder, E.J. 1979. Endive and chicoty. Leafy salad vegetables. AVI, Westport, Conn. p. 171-194.

Sarrazyn, R. 1976. Study of varieties with Belgian endive without a comparison with soil covering. Proc. Eucarpia Meet. Leafy Vegetables, Wageningen, Holland, 15-18 Mar. p. 32-39.

Sterrett, S.B. and C.P. Savage. 1989. A forcing unit for Belgian endive. HortScience 24:703. 